\title{
UV photolysis kinetics of sulfonamides in aqueous solution based on optimized fluence quantification
}

\author{
Junfeng Lian ${ }^{a}$, Zhimin Qiang ${ }^{a, *}$, Mengkai Li ${ }^{a}$, James R. Bolton ${ }^{b}$, \\ Jiuhui Qu ${ }^{a}$ \\ ${ }^{a}$ Key Laboratory of Drinking Water Science and Technology, Research Center for Eco-Environmental Sciences, \\ Chinese Academy of Sciences, 18 Shuang-qing Road, Beijing 100085, China \\ ${ }^{\mathrm{b}}$ Department of Civil and Environmental Engineering, University of Alberta, Edmonton, AB T6G 2W2, Canada
}

\section{A R T I C L E I N F O}

\section{Article history:}

Received 17 September 2014

Received in revised form

4 January 2015

Accepted 15 February 2015

Available online 25 February 2015

Keywords:

Sulfonamides

UV photolysis

Kinetic parameters

Quasi-collimated beam apparatus

Micro fluorescent silica detector

\begin{abstract}
A B S T R A C T
The ultraviolet (UV) photolysis kinetics of eight sulfonamide (SA) antibiotics was investigated in a quasi-collimated beam apparatus. By using a micro fluorescent silica detector to monitor online the dynamic irradiance fluctuation, the accuracy in fluence quantification could be increased by up to $15 \%$. Solution $\mathrm{pH}$ governed the speciation of selected SAs, thus impacting significantly their molar absorption coefficients $(\varepsilon)$, fluence-based photolysis rate constants $\left(k^{\prime}\right)$, and quantum yields. An increasing $\mathrm{pH}$ induced a hyperchromic effect and a blue shift of the UV-Vis absorption spectra of selected SAs, thus causing the anionic species to show a relatively higher specific $\varepsilon$ value than the neutral species at $254 \mathrm{~nm}$. On UV exposure, the photodegradation of selected SAs all followed pseudo-first order reaction kinetics. The SAs with a penta-heterocycle, because of their higher electron densities, exhibited an obviously higher photodegradation rate than those with a hexaheterocycle. The specific $k^{\prime}$ values of the neutral and anionic species were in the ranges of $(0.30-14.49) \times 10^{-3}$ and $(0.61-20.90) \times 10^{-3} \mathrm{~cm}^{2} \mathrm{~mJ}^{-1}$, respectively. With the specific $k^{\prime}$ values obtained, it is estimated that only part of SAs can be photodegraded during UV disinfection of water and wastewater, so an advanced oxidation process is necessary if a higher removal of selected SAs is to be achieved.
\end{abstract}

(C) 2015 Elsevier Ltd. All rights reserved.

\section{Introduction}

Over the last few decades, the occurrence, fate and risk of residual antibiotics in the environment have received great attention. The pollution sources of antibiotics are mainly discharges from sewage treatment plants, pharmaceutical industrial wastewater, and landfill leachate (Dirany et al., 2012). Sulfonamides (SAs) represent one important class of antibiotics commonly used in veterinary and human medical practices because of their broad antimicrobial spectrum, strong antibacterial activity, stable chemical property, and low price (Hess et al., 1999; Huang et al., 2012). SAs are amphoteric and water-soluble compounds with a high environmental mobility (Dirany et al., 2012), so their traces are ubiquitous in almost all waters (e.g., waste, surface, ground, and drinking waters) (Lanuza, 2010; Capdeville and Budzinski, 2011; Fatta-Kassinos et al., 2011). Even though no direct

\footnotetext{
* Corresponding author. Tel.: +8610 62849632; fax: +861062923541.

E-mail address: qiangz@rcees.ac.cn (Z. Qiang). http://dx.doi.org/10.1016/j.watres.2015.02.026
}

0043-1354/@ 2015 Elsevier Ltd. All rights reserved. 
human health effects have been reported (Le et al., 2005), SAs tend to bio-accumulate and have potential adverse effects on aquatic and terrestrial ecosystems by interrupting the normal activities of some microorganisms as well as developing and spreading antibiotic resistance genes (Elmolla and Chaudhuri, 2010; Rivas et al., 2011; Yuan et al., 2011).

In recent years, ultraviolet (UV) technology has been increasingly applied for the disinfection of water and wastewater because of its inherent advantages such as high inactivation efficiency of pathogenic microorganisms, few disinfection byproducts production, small space-occupancy, and easy operation and maintenance (Parkinson et al., 2001; Pereira et al., 2007; Li and Blatchley III, 2008). UV can not only inactivate water-borne microorganisms through damaging their DNA and/or RNA but also decompose many micropollutants through photochemical reactions (Burrows et al., 2002). Moreover, photolysis is also an important process accounting for natural attenuation of many contaminants in the photic zone of water bodies.

To explore UV disinfection or photolysis kinetics, a quasicollimated beam apparatus (qCBA) is often used in benchscale studies and a corresponding equation (i.e., qCBA equation) is adopted to calculate the average irradiance in a test aqueous solution (Bolton and Stefan, 2002; Bolton and Linden, 2003). Although the central irradiance on the solution surface is initially measured by a calibrated radiometer, this equation can not respond to the dynamic irradiance fluctuation and is likely to induce indeterminate errors. In our previous work, a novel micro-fluorescent silica detector (MFSD) was developed with distinct merits of high chemical stability (made from durable silica material), low thermal expansion coefficient $\left(5.5 \times 10^{-7}\right.$ per $\left.{ }^{\circ} \mathrm{C}\right)$, extremely fast response $(1 \mu \mathrm{s})$, and very small volume $\left(0.07 \mathrm{~mm}^{3}\right.$ ) (Li et al., 2011, 2012). As an ideal sensor, the MFSD was employed in this study to monitor online the dynamic irradiance fluctuation so as to improve the accuracy in determining the photolysis kinetics.

Previous studies have found that the direct photolysis of SAs is highly pH-dependent because the acid-base speciation of SAs in aqueous solution affects their optical properties and reactivity (Boreen et al., 2004; Avisar et al., 2010; Baeza and Knappe, 2011). Under natural sunlight, the photodegradation rates of four SAs, including sulfamethoxazole (SMX), sulfathiazole (STZ), sulfamethizole (SML), and sulfisoxazole (SFX), not only depended on their protonation states but also exhibited a wide range of variation among these similarly structured antibiotics (Boreen et al., 2004). Under irradiation of a medium-pressure UV lamp (emitting polychromatic beams), the removal of SMX was significantly enhanced in acidic $\mathrm{pH}$ conditions (Avisar et al., 2010; Lester et al., 2012). Baeza and Knappe (2011) measured the pseudo-first order photolysis rates of SMX, sulfamethazine (SMN), and sulfadiazine (SDA) under irradiation of low-pressure UV lamps (emitting monochromatic $254 \mathrm{~nm}$ beams) at three $\mathrm{pH}$ values (i.e., 3.6, 7.85, and 9.7). However, to date, the fluence-based specific rate constants for direct UV photolysis of SAs have never been reported. These specific rate constants, independent of solution $\mathrm{pH}$ and free of matrix interference, can be very useful for predicting the fate of SAs during UV disinfection of water and wastewater.

This study aims to determine accurately the direct UV $(254 \mathrm{~nm})$ photolysis kinetics of eight selected SAs in a standard
qCBA. Based on the $\mathrm{pH}$-dependent speciation of selected SAs in aqueous solution, specific kinetic parameters including the molar absorption coefficient $(\varepsilon)$, fluence-based photolysis rate constant $\left(k^{\prime}\right)$, and quantum yield $(\phi)$ could be obtained through model simulations of experimental data. With the specific $k^{\prime}$ values available, the removal efficiencies of selected SAs during UV disinfection of water and wastewater were readily predicted under a given $\mathrm{pH}$ condition. This study can also help estimate the contribution of direct photolysis to the removal of SAs in UV-based advanced oxidation processes (e.g., $\mathrm{UV} / \mathrm{H}_{2} \mathrm{O}_{2}, \mathrm{UV} / \mathrm{O}_{3}$ ).

\section{Materials and methods}

\subsection{Chemicals}

The major physicochemical properties of eight selected SAs are shown in Table 1, including SMN, sulfamerazine (SMR), SDA, sulfachloropyridazine (SCP), SMX, STZ, SML, and SFX. SMN was purchased from Thermo Fisher Scientific (Fair Lawn, NJ, USA), and all other SAs were from Sigma-Aldrich (St. Louis, MO, USA). The purity of each SA was greater than $99.0 \%$, except STZ $(\geq 98.0 \%)$. High performance liquid chromatography grade methanol and acetonitrile were obtained from Thermo Fisher Scientific, and formic acid $(\geq 99.0 \%)$ from Dikma Technologies (Lake Forest, CA, USA). All other chemicals, of at least analytical grade, were provided by Beijing Chemical Reagents Company (Beijing, China). The stock solutions of each SA $\left(100 \mathrm{mg} \mathrm{L}^{-1}\right)$ were freshly prepared with ultrapure water produced by an Advantage A10 water purification system (Millipore, Billerica, MA, USA) with a resistivity of $>18.2 \mathrm{M} \Omega \mathrm{cm}$.

\subsection{Experimental procedures}

It is known that a compound with Henry's constant $\left(H_{c}\right)$ of less than $1 \times 10^{-4} \mathrm{~atm} \mathrm{~m}^{3} \mathrm{~mol}^{-1}$ and $H_{\mathrm{c}} / K_{\text {ow }}$ ( $K_{\text {ow }}=$ octanol-water partition coefficient) of less than $1 \times 10^{-9} \mathrm{~atm} \mathrm{~m}^{3} \mathrm{~mol}^{-1}$ has a low volatilization potential (Birkett and Lester, 2003). Because all the selected SAs have considerably lower $H_{c}$ and $H_{c} / K_{\text {ow }}$ than the critical values (Table 1 ), their volatilization during UV photolysis experiments could be neglected.

UV photolysis experiments were performed at room temperature (the heat from the UV exposure had little effect on the test solution temperature) in a standard qCBA (Onyx Environmental Products Inc., Tianjin, China) equipped with a low-pressure high-output mercury lamp $(85 \mathrm{~W}, 34 \% \mathrm{UVC}$ efficiency; Light Sources Co., Orange, CA, USA) emitting monochromatic light at $254 \mathrm{~nm}$ (Fig. 1). The UV lamp was initially warmed up for about $30 \mathrm{~min}$ to ensure a relatively stable output. A Petri dish of $6.0 \mathrm{~cm}$ internal diameter was used as the reactor. A magnetic stirring apparatus and a small stirring bar $(3 \times 12 \mathrm{~mm})$ were utilized with a gentle stirring rate to avoid a vortex. The SA solution volume was $20 \mathrm{~mL}$, and the vertical distance from the UV lamp to the top of the test solution was $57.2 \mathrm{~cm}$. The measurement of $\varepsilon$ was repeated at least five times, and the UV photolysis experiments were conducted in triplicate.

The photolysis rate constants are usually expressed per unit of reaction time, which often leads to irreproducible 
Table 1 - Major physicochemical properties of selected sulfonamides.

\begin{tabular}{|c|c|c|c|c|}
\hline SAs & Structure & $\mathrm{pK}_{a}$ & $\log K_{\text {ow }}{ }^{a}$ & $\mathrm{H}_{\mathrm{c}}{ }^{\mathrm{a}}\left(\mathrm{atm} \mathrm{m} \mathrm{mol}^{3} \mathrm{mo}^{-1}\right.$ \\
\hline Sulfamethazine (SMN) & & $\begin{array}{l}2.07 \pm 0.30 \\
7.49 \pm 0.13^{b}\end{array}$ & 0.19 & $3.05 \times 10^{-13}$ \\
\hline Sulfamerazine (SMR) & & $\begin{array}{l}2.82 \pm 0.31 \\
6.84 \pm 0.30^{c}\end{array}$ & 0.14 & $1.75 \times 10^{-10}$ \\
\hline Sulfadiazine (SDA) & & $\begin{array}{l}1.57 \pm 0.10 \\
6.50 \pm 0.30^{c}\end{array}$ & -0.09 & $1.58 \times 10^{-10}$ \\
\hline Sulfachloropyridazine (SCP) & & $\begin{array}{l}1.36 \pm 0.10 \\
5.90 \pm 0.30^{c}\end{array}$ & 0.31 & $2.05 \times 10^{-12}$ \\
\hline Sulfamethoxazole (SMX) & & $\begin{array}{l}1.85 \pm 0.30 \\
5.60 \pm 0.04^{b}\end{array}$ & 0.89 & $9.56 \times 10^{-13}$ \\
\hline Sulfathiazole (STZ) & & $\begin{array}{l}2.01 \pm 0.30 \\
7.11 \pm 0.09^{b}\end{array}$ & 0.05 & $5.85 \times 10^{-14}$ \\
\hline Sulfamethizole (SML) & & $\begin{array}{l}1.86 \pm 0.30 \\
5.29 \pm 0.04^{b}\end{array}$ & 0.54 & $2.63 \times 10^{-14}$ \\
\hline Sulfisoxazole (SFX) & & $\begin{array}{l}1.52 \pm 0.10 \\
4.83 \pm 0.50^{\circ}\end{array}$ & 1.01 & $1.06 \times 10^{-12}$ \\
\hline
\end{tabular}

results because several parameters (e.g., lamp irradiance, light pathlength, and solution absorbance) can vary significantly in different lab settings. Thus, fluence-based photolysis rate constants, initially introduced by Bolton and Stefan (2002), were adopted in this study.

\subsection{Optimized fluence quantification}

The average irradiance in the test solution, $E_{\text {avg }}\left(\mathrm{mW} \mathrm{cm}^{-2}\right)$, can be determined by the qCBA equation (Bolton and Stefan, 2002):

$E_{\text {avg }}=E_{0} \times \mathrm{PF} \times \mathrm{RF} \times \mathrm{WF} \times \mathrm{DF}$

where $E_{o}=$ irradiance reading $\left(\mathrm{mW} \mathrm{cm}^{-2}\right)$ of a radiometer (ZG4A, China Building Materials Academy, Beijing, China) calibrated by the National Institute of Metrology (Beijing, China) at the top center of the test solution; $\mathrm{PF}=$ Petri factor that corrects for the horizontal divergence (Fig. S1); RF = reflection factor (i.e., 0.975) that corrects for the reflection at the water/ air interface; $\mathrm{WF}=$ water factor that corrects for the solution absorbance; and DF = divergence factor that corrects for the vertical divergence.

The dynamic irradiance fluctuation was online monitored by an MFSD installed at the bottom of the collimating tube, with the photosensitive window facing the UV beams (Fig. 1). The monitoring data were automatically collected and stored by a data acquisition switch unit (VX2103R/C2/U/TP1, Hangzhou Pangu Automation System Co., Ltd., Zhejiang, China) at a frequency of once per minute. The fluence was calculated from the integral of the fluctuating real-time irradiance (monitored by MFSD) versus the UV exposure time.

\subsection{Analytical methods}

The concentrations of selected SAs were analyzed with an ultra-performance liquid chromatography-tandem mass spectrometry (UPLC-MS/MS) system (Agilent 1290 Infinity LC, Agilent 6420 Triple Quad LC/MS detector) coupled with an SBC18 column $(2.1 \mathrm{~mm} \times 50 \mathrm{~mm}, 1.8 \mu \mathrm{m}$ particle size) (Agilent 


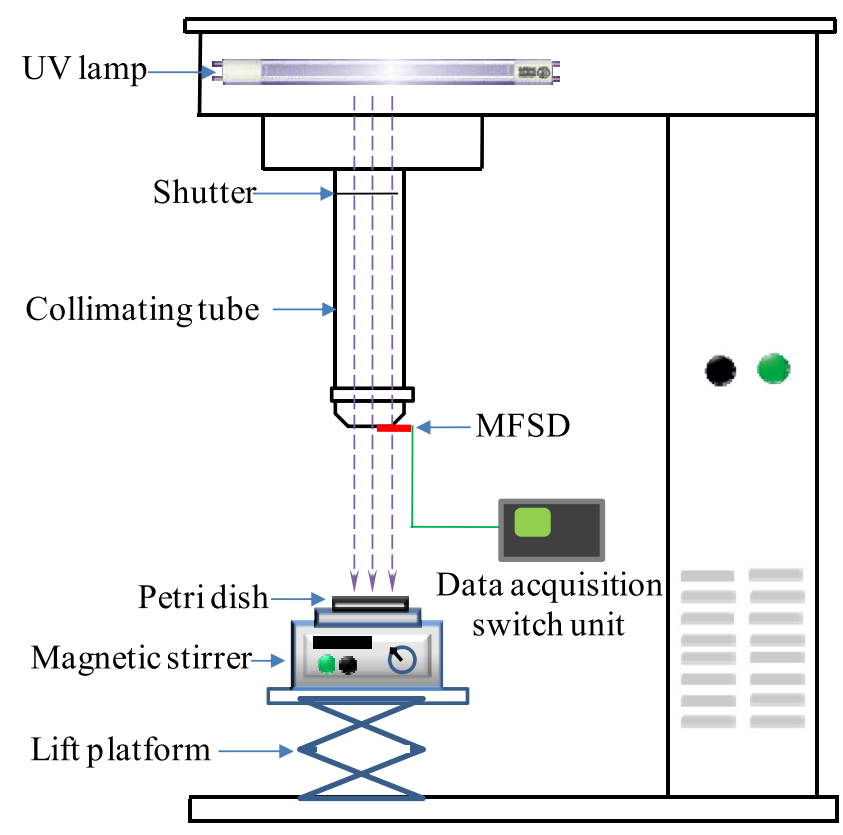

Fig. 1 - Schematic diagram of the quasi-collimated beam apparatus ( $q C B A$ ) online monitored by a micro fluorescent silica detector (MFSD).

Technologies, Wilmington, DE, USA). The injection volume was $5 \mu \mathrm{L}$. The mobile phase was a mixture of $0.2 \%$ formic acid in water $(\mathrm{A})$ and acetonitrile $(\mathrm{B})(\mathrm{v} / \mathrm{v}=65: 35)$ at a flow rate of 0.2 or $0.3 \mathrm{~mL} \mathrm{~min}^{-1}$. The MS was operated under the following conditions: positive electrospray ionization mode, capillary voltage $4.0 \mathrm{kV}$, drying gas temperature $300^{\circ} \mathrm{C}$, drying gas flow rate $12 \mathrm{~L} \mathrm{~min} \mathrm{~m}^{-1}$, and nebulizing gas pressure 40 psi. For each analyte, the precursor and product ions, fragmentor voltage, and collision energies were all optimized under the multiple reaction monitoring mode (Table S1).

The solution $\mathrm{pH}$ was measured with an FE-20K pH meter (Mettler Toledo, Zurich, Switzerland). The spectral scan and absorbance measurement were performed on a UV-Vis spectrophotometer (DR5000, Hach Company, Loveland, CO, USA). The dissolved organic carbon (DOC) concentration was analyzed by a Total Organic Carbon Analyzer (TOC- $\mathrm{V}_{\mathrm{CPH}}$, Shimadzu, Kyoto, Japan).

\section{Results and discussion}

\subsection{Optimized fluence quantification}

As indicated in Eq. (1), the average irradiance $\left(E_{\text {avg }}\right)$ is a function of the irradiance at the top center of the test solution $\left(E_{0}\right)$ and several correction factors including PF, RF, WF, and DF. According to the definitions, the RF and DF were constant; at the meantime, the fluctuations of PF (Fig. S2) and WF could be neglected during the UV photolysis experiment. As a result, the values of $E_{\text {avg }}$ and $E_{o}$ would have synchronous and proportional fluctuations. In addition, the light source in a qCBA can be considered as a point source because the UV beams are constrained to be nearly parallel by the collimating tube. The irradiances at two different test points are proportional according to the point source equation (Bolton, 2010):

$E=\frac{P_{\Phi}}{4 \pi r^{2}}$

where $E=$ irradiance $\left(\mathrm{W} \mathrm{m}^{-2}\right) ; P_{\Phi}=$ radiant power of the point source $(\mathrm{W})$; and $r=$ radial distance from the point source $(\mathrm{m})$. Therefore, it is feasible to accurately determine the real-time average irradiance in the test solution based on the initial average irradiance calculated by Eq. (1) and the irradiance fluctuation monitored by the MFSD that was installed at the bottom of the collimating tube (Fig. 1).

Fig. 2 shows three typical cases illustrating the real-time irradiance fluctuations and the fluences comparatively determined with the optimized method and qCBA equation. The irradiance may continuously decrease (Case 1) or increase (Case 3) with certain fluctuations, leading to an overestimated or underestimated fluence if calculated by the qCBA equation.

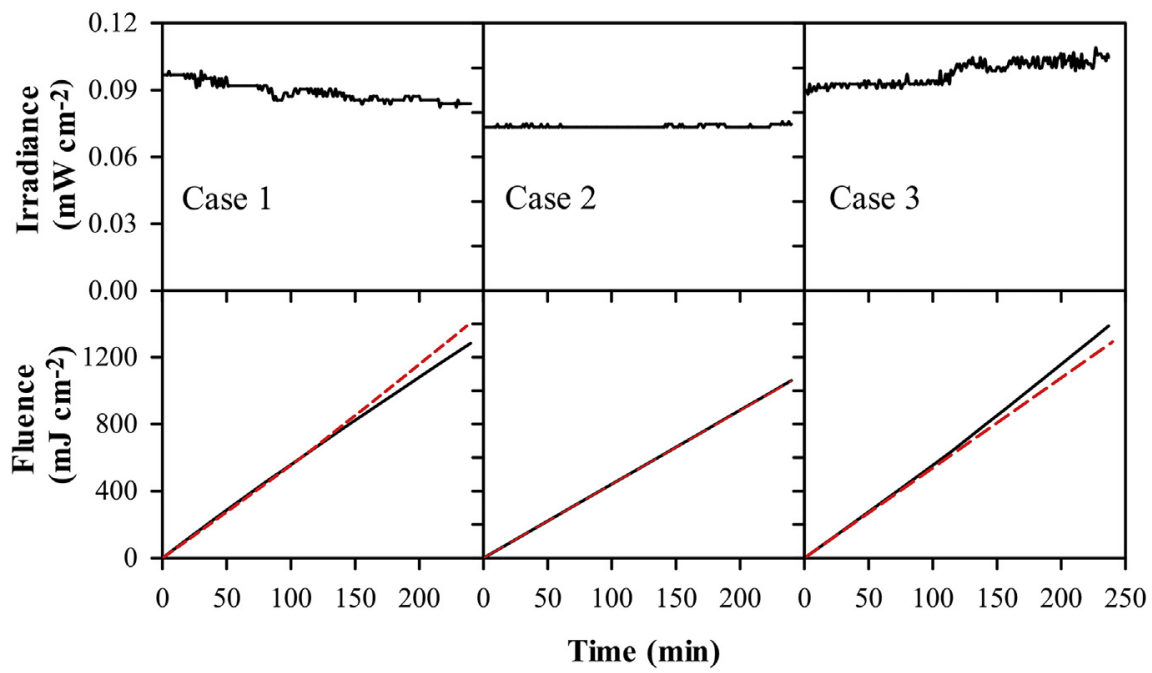

Fig. 2 - Typical cases illustrating the MFSD-monitored irradiance fluctuations (top) and the fluences comparatively determined with the optimized method (solid line) and qCBA equation (dashed line) (bottom). 
The MFSD monitoring data indicate that the irradiance fluctuation was obvious in most cases, as compared to the rare occurrence of a relatively stable fluence throughout the test period (Case 2). The error in fluence quantification differed in different cases, as the irradiance fluctuation could arise from the variations in lamp chamber temperature, lamp service time, lamp quality, and electrical voltage. The central factor is usually the lamp chamber temperature of the qCBA, which significantly affects the mercury vapor pressure in the lamp and consequently induces a fluctuation of the lamp output (Qiang et al., 2013). Through online monitoring the irradiance fluctuation with the MFSD, the optimized method could increase the accuracy in fluence quantification $(\delta)$ by up to $15 \%$, as calculated below:

$\delta=\frac{\left|F_{\mathrm{opt}}-F_{\mathrm{qCBA}}\right|}{F_{\mathrm{opt}}} \times 100 \%$

where $F_{\text {opt }}$ and $F_{q \text { CBA }}\left(\mathrm{mJ} \mathrm{cm}{ }^{-2}\right)$ are the fluences determined by the optimized method and qCBA equation, respectively.

\subsection{Determination of molar absorption coefficients}

The molar absorption coefficient is defined via the Lambert-Beer Law:

$\mathrm{A}=\varepsilon \mathrm{Cl}$

where $\mathrm{A}=$ solution absorbance at a certain wavelength (254 $\mathrm{nm}$ in this study); $\varepsilon=$ molar absorption coefficient $\left(\mathrm{M}^{-1} \mathrm{~cm}^{-1}\right)$; and $\mathrm{C}=$ analyte concentration $(\mathrm{M})$. Hence, the overall absorbance of an SA solution is equal to the sum of the specific absorbance of each existing species under a certain $\mathrm{pH}$ condition:

$\mathrm{A}=\mathrm{A}_{\mathrm{SA}^{+}}+\mathrm{A}_{\mathrm{SA}^{0}}+\mathrm{A}_{\mathrm{SA}^{-}}$

where the footnotes $\mathrm{SA}^{+}, \mathrm{SA}^{0}$ and $\mathrm{SA}^{-}$represent the cationic, neutral and anionic species, respectively. From Eqs. (4) and (5), one has:

$\varepsilon=\varepsilon_{\mathrm{SA}^{+}} \alpha_{\mathrm{SA}^{+}}+\varepsilon_{\mathrm{SA}^{0}} \alpha_{\mathrm{SA}^{0}}+\varepsilon_{\mathrm{SA}^{-}} \alpha_{\mathrm{SA}^{-}}$

where $\alpha=$ distribution coefficient. The speciation diagrams of selected SAs as a function of $\mathrm{pH}$ are shown in Fig. S3.

For water and wastewater treatment, the typical $\mathrm{pH}$ usually ranges from 6.5 to 9.5, where the neutral and anionic species predominate in an SA solution (Fig. S3). Fig. 3 shows that in the studied $\mathrm{pH}$ range of $4-12$, the $\varepsilon$ values of selected SAs depended highly on the solution $\mathrm{pH}$. In the vicinity of the $\mathrm{pK}_{\mathrm{a}, 2}$ of an SA (Table 1), a remarkable increase in $\varepsilon$ was observed; while in other $\mathrm{pH}$ regions, the $\varepsilon$ was relatively stable. This result reflects that the different species of an SA should have different $\varepsilon$ values. Since the cationic species contributed insignificantly to the overall $\varepsilon$ above $\mathrm{pH} 4$, the specific $\varepsilon$ values of the neutral and anionic species could be obtained through regression analysis with Microsoft Excel 2010. Results indicate that the overall $\varepsilon$ values experimentally measured could be well fitted by Eq. (6) (Fig. 3), and the specific $\varepsilon$ values were in the ranges of $(10.8-17.0) \times 10^{3}$ and $(17.1-24.1) \times 10^{3} \mathrm{M}^{-1} \mathrm{~cm}^{-1}$ for the neutral and anionic species, respectively (Table 2). Baeza and Knappe (2011) also found that the anionic species of SMX, SMN and SDA exhibited higher $\varepsilon$ values (at $254 \mathrm{~nm}$ ) than their respective neutral species. The overall $\varepsilon$ values measured by these researchers under different $\mathrm{pH}$ conditions agreed well with our results.

On a UV-Vis spectral scan, the photons would be absorbed by the $n$ (lone-pair) and $\pi$ electrons of an SA in the test solution, thus inducing $\pi \rightarrow \pi^{*}, n \rightarrow \pi^{*}$, and $n \rightarrow \sigma^{*}$ electron transitions. Fig. S4 shows the UV-Vis absorption spectra of selected $\mathrm{SAs}$ at various $\mathrm{pH}$ values approximately ranging from 3 to 11 . The absorption peak(s) of selected SAs appeared in the wavelength range of about $225-300 \mathrm{~nm}$, whereas the absorption peak below $200 \mathrm{~nm}$ was most probably caused by impurities in water. As the $\mathrm{pH}$ increased, the sulfinol group $(-\mathrm{S}(=\mathrm{O}) 2-\mathrm{NH}-)$ was gradually deprotonated to liberate the lone-pair electrons of its $\mathrm{N}$ atom (auxochrome), which consequently exerted a hyperchromic effect on the absorption peak(s). For the neutral species, the sulfinol-N atom had only one lone-pair of electrons, which could draw closer the $\pi$ electrons of the sulfonyl and heterocycle groups to lower the total energy level. As the $\mathrm{pH}$ increased above the $\mathrm{pK}_{\mathrm{a}, 2}$, the anionic species started to predominate, so the sulfinol-N atom would have two lone-pairs of electrons with each pair being able to conjugate with the $\pi$ electrons of the sulfonyl and heterocycle groups $(p-\pi$ conjugation). The resulting strong repulsion between the two lone-pairs of electrons tended to

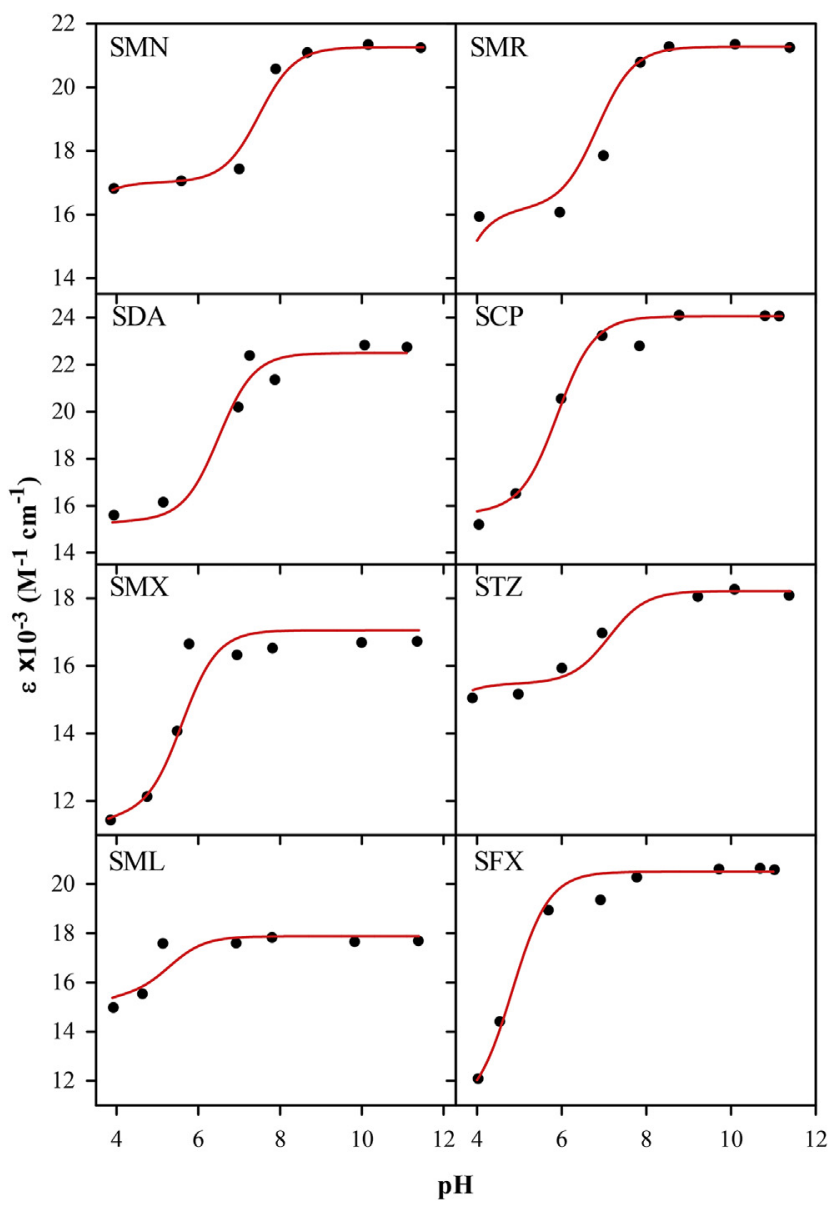

Fig. 3 - Molar absorption coefficient $(\varepsilon)$ of each SA as a function of $\mathrm{pH}\left(\mathrm{C}_{\mathrm{SA}}=20 \mathrm{mg} \mathrm{L}^{-1}\right)$. The symbols and curves represent the experimental data and model-fitting results, respectively. 
Table 2 - Specific kinetic parameters for UV photolysis of selected SAs in aqueous solution.

\begin{tabular}{|c|c|c|c|c|c|c|}
\hline \multirow[t]{2}{*}{ SAs } & \multicolumn{2}{|c|}{$\varepsilon \times 10^{-3}\left(\mathrm{M}^{-1} \mathrm{~cm}^{-1}\right)$} & \multicolumn{2}{|c|}{$k^{\prime} \times 10^{3}\left(\mathrm{~cm}^{2} \mathrm{~mJ}^{-1}\right)$} & \multicolumn{2}{|c|}{$\phi \times 10^{2}$} \\
\hline & $\mathrm{SA}^{0}$ & $\mathrm{SA}^{-}$ & $\mathrm{SA}^{0}$ & $\mathrm{SA}^{-}$ & $\mathrm{SA}^{0}$ & $\mathrm{SA}^{-}$ \\
\hline SMN & 17.0 & 21.3 & 0.30 & 1.24 & 0.36 & 1.19 \\
\hline SMR & 16.1 & 21.3 & 0.43 & 0.80 & 0.55 & 0.77 \\
\hline SDA & 15.3 & 22.5 & 0.43 & 0.70 & 0.58 & 0.63 \\
\hline SCP & 15.7 & 24.1 & 0.56 & 0.61 & 0.73 & 0.52 \\
\hline SMX & 11.5 & 17.1 & 14.49 & 3.80 & 25.73 & 4.55 \\
\hline STZ & 15.5 & 18.2 & 1.17 & 10.98 & 1.54 & 12.33 \\
\hline SML & 15.4 & 17.9 & 0.37 & 3.44 & 0.49 & 3.93 \\
\hline SFX & 10.8 & 20.5 & 11.61 & 20.90 & 21.95 & 20.85 \\
\hline
\end{tabular}

raise the total energy level and consequently cause a blue shift of the absorption spectra (i.e., the maximum absorption peak moves toward a shorter wavelength). Fig. S4 reflects the combined action of the hyperchromic effect and the blue shift with an increasing $\mathrm{pH}$, implying that the anionic species had a higher specific $\varepsilon$ value than the neutral species at $254 \mathrm{~nm}$ (Table 2).

\subsection{Direct UV photolysis of sulfonamides}

The UV photolysis experiments of selected SAs, with an initial concentration of $500 \mu \mathrm{g} \mathrm{L}^{-1}$, were conducted individually in the qCBA. The solution $\mathrm{pH}$ was not controlled, which only changed by less than $0.3 \mathrm{pH}$ units after the photolysis test. Fig. 4 shows that the photodegradation of all selected SAs followed the pseudo-first order kinetics, and the removal efficiency ranged from $35 \%$ to $100 \%$ after $4 \mathrm{~h}$ of UV exposure (i.e., an equivalent fluence range of about $1100-1600 \mathrm{~mJ} \mathrm{~cm}{ }^{-2}$ for different SAs). It is seen that at a typical fluence for

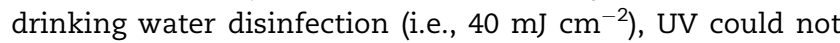
degrade the SAs effectively, exhibiting a maximum removal of $60 \%$ for SFX and less than $15 \%$ removal for all other SAs. In addition, the fluence required for $90 \%$ removal of selected SAs was calculated as follows $\left(\mathrm{mJ} \mathrm{cm}^{-2}\right): 6308(\mathrm{SMN}), 3956$ (SMR), 3473 (SDA), 3275 (SCP), 513 (SMX), 807 (STZ), 761 (SML), and 102 (SFX).

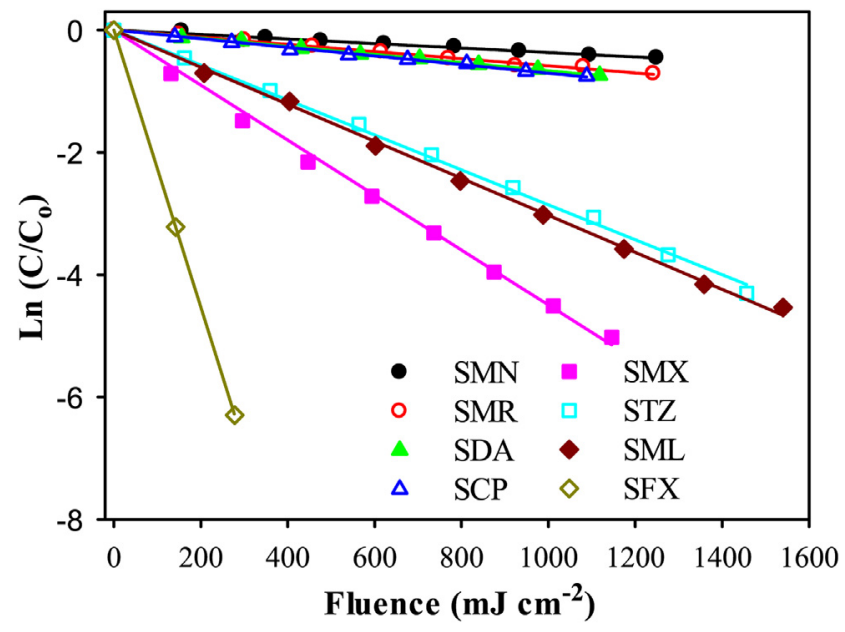

Fig. 4 - Photodegradation of selected SAs as a function of fluence $\left(\mathrm{C}_{\mathrm{SA}, \mathrm{o}}=500 \mu \mathrm{g} \mathrm{L}^{-1}, \mathrm{pH}_{\mathrm{o}}=5.8-6.6\right)$.
Note that the SAs with a penta-heterocycle (i.e., SMX, STZ, SML, and SFX) exhibited an obviously higher photodegradation rate than those with a hexa-heterocycle (i.e., SMN, SMR, SDA, and SCP), which was probably attributed to different electron densities of the two types of heterocycles. According to the Hückel Law, the O or S atom located at the first position of a penta-heterocycle (e.g., SMX and SML, Scheme 1) could donate its lone-pair electrons to form a delocalized $\pi$ bond of a planar ring with aromatic properties, thus causing the penta-heterocycle to possess a greater electron density than the hexa-heterocycle. On UV photolysis, the absorbed photons would excite the $n$ and $\pi$ electrons of an SA as above mentioned (Section 3.2), and then induce the subsequent degradation. Hence, the photodegradation rate is positively related to the electron density of an SA.

Among the four SAs with a hexa-heterocycle, SCP showed the highest photodegradation rate. Though the $\mathrm{Cl}$ atom has a strong electron-withdrawing ability, its three lone-pairs of electrons could form $p-\pi$ conjugation with the $\pi$ electrons of the diazine ring to enhance the photolytic reactivity of SCP. Moreover, for the SAs with a penta-heterocycle, SFX and SMX showed a higher photodegradation rate than STZ and SML. This was probably attributed to the $\mathrm{O}$ atom in the heterocycles, which has the strongest electronegativity among the three heteroatoms (i.e., O, S, and N).

Fig. 5 shows the fluence-based photolysis rate constants $\left(k^{\prime}\right)$ of selected SAs as a function of solution pH (buffered with $5 \mathrm{mM}$ phosphate). Results indicate again that at a fixed $\mathrm{pH}$, the SAs with a penta-heterocycle exhibited a higher $k^{\prime}$ than those with a hexa-heterocycle. At a certain $\mathrm{pH}$, the overall $k^{\prime}$ of an SA was equal to the sum of the specific $k^{\prime}$ of each existing species multiplied by its corresponding distribution coefficient, as expressed by Eq. (7). The derivation of this equation is detailed in Text $\mathrm{S} 1$.

$k^{\prime}=k_{\mathrm{SA}^{+}}^{\prime} \alpha_{\mathrm{SA}^{+}}+k_{\mathrm{SA}^{0}}^{\prime} \alpha_{\mathrm{SA}^{0}}+k_{\mathrm{SA}^{-}}^{\prime} \alpha_{\mathrm{SA}^{-}}$

Once the $k^{\prime}$ (either overall or specific) of an SA was determined, the corresponding quantum yield $(\phi)$ could be readily calculated via Eq. (8) (Bolton and Stefan, 2002):

$\phi=\frac{10 \times \mathrm{U}_{254} k^{\prime}}{\varepsilon \ln (10)}$

where $\mathrm{U}_{254}=$ molar photon energy $\left(4.7153 \times 10^{5} \mathrm{~J} \mathrm{E}^{-1}\right.$ at $254 \mathrm{~nm})$.

The modeling results indicate that the experimental data could be fitted quite well by Eq. (7) (Fig. 5). As mentioned above, the cationic species could be neglected above $\mathrm{pH} 4$. The specific $k^{\prime}$ values were then determined to be in the ranges of $(0.30-14.49) \times 10^{-3}$ and $(0.61-20.90) \times 10^{-3} \mathrm{~cm}^{2} \mathrm{~mJ}^{-1}$ for the neutral and anionic species, respectively (Table 2$)$. When the specific $\varepsilon$ and $k^{\prime}$ values were determined, by using Eq. (8), the
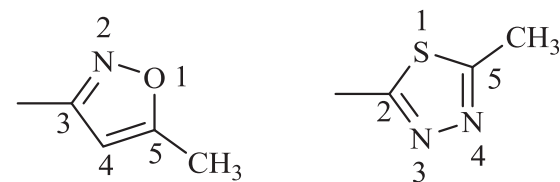

Scheme 1 - Heteroatom positions in two pentaheterocycles. 


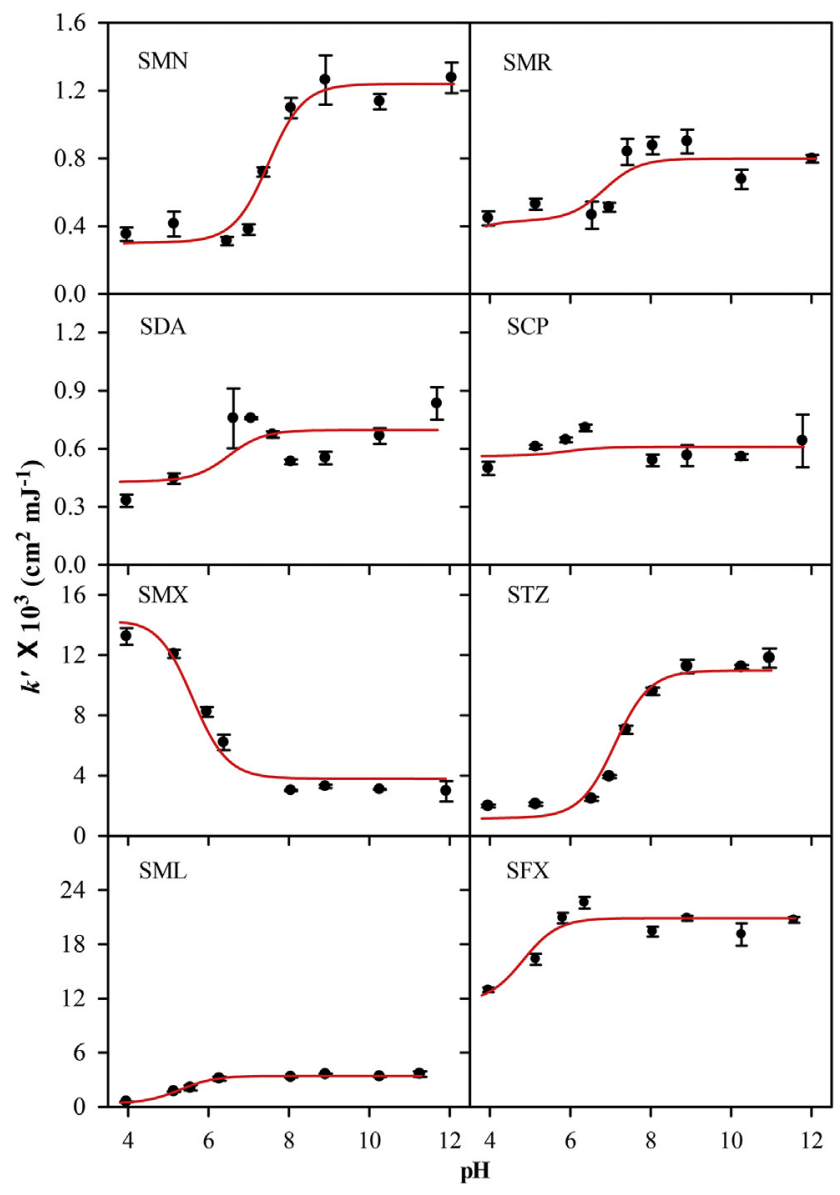

Fig. 5 - Fluence-based photolysis rate constants $\left(k^{\prime}\right)$ of selected SAs as a function of $\mathrm{pH}\left(\mathrm{C}_{\mathrm{SA}, \mathrm{o}}=500 \mu \mathrm{g} \mathrm{L}^{-1}\right)$. The symbols and curves represent the experimental data and model-fitting results, respectively.

specific $\phi$ values for the neutral and anionic species were calculated to be in the ranges of $(0.36-25.73) \times 10^{-2}$ and $(0.52-20.90) \times 10^{-2}$, respectively (Table 2 ).

In addition, most of the selected SAs (i.e., SMN, SMR, STZ, SML, and SFX) exhibited an increasing overall $k^{\prime}$ as the $\mathrm{pH}$ increased; however, SMX showed an opposite trend; and meanwhile, SDA and SCP showed irregularly-shaped curves (Fig. 5). Boreen et al. (2004) also found that SMX was degraded more rapidly in the neutral form than in the anionic form under natural sunlight, but it turned into the opposite side for STZ and SML. Baeza and Knappe (2011) reported that under UV $(254 \mathrm{~nm})$ irradiation, the pseudo-first order photolysis rate constant of SDA was higher at a nearly neutral $\mathrm{pH}$ (7.85) than that at an acidic (3.6) or alkaline (9.7) $\mathrm{pH}$; the photolysis rate constant of SMN increased as the $\mathrm{pH}$ increased; while SMX was photodegraded more rapidly in an acidic condition. These results agree well with what was observed in this study.

\subsection{Discussion on potential applications}

With the specific $k^{\prime}$ values obtained, the overall $k^{\prime}$ of an SA can be easily calculated with Eq. (7) at a pH typical for water and wastewater treatment to predict the SA removal during

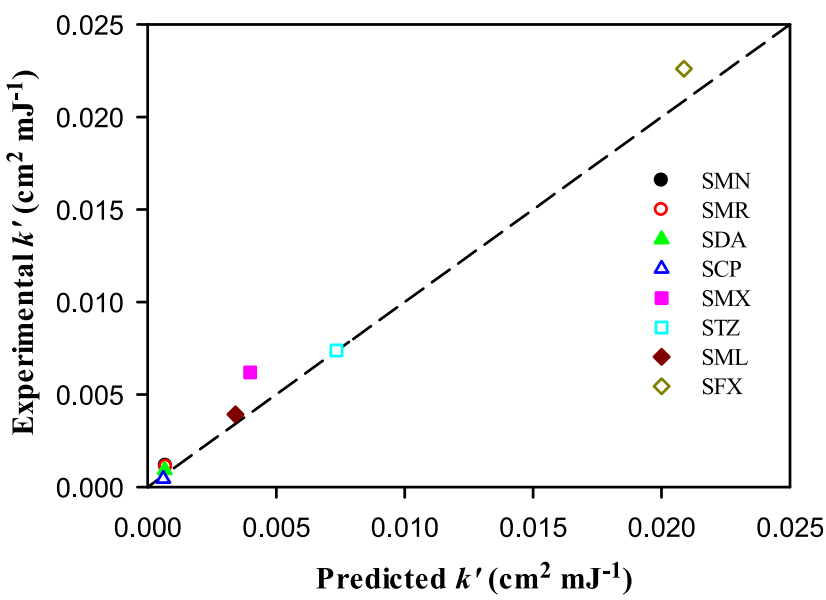

Fig. 6 - Comparison of the experimental and predicted fluence-based photolysis rate constants $\left(k^{\prime}\right)$ $\left(\mathrm{C}_{\mathrm{SA}, \mathrm{o}}=500 \mu \mathrm{g} \mathrm{L}^{-1}, \mathrm{pH}=7.3\right)$. The diagonal line denotes that the experimentally measured and model predicted values are identical.

UV disinfection. Verification tests were performed in a water collected from a local drinking water treatment plant (No. 9 Waterworks, Beijing) after the activated carbon filtration process. The filtered water $\left(\mathrm{pH}=8.35, \mathrm{UV}_{254}=0.020 \mathrm{~cm}^{-1}\right.$, and $\mathrm{DOC}=0.99 \mathrm{mg} \mathrm{L}^{-1}$ ) was buffered with $5 \mathrm{mM}$ phosphate and then spiked with the selected SAs (500 $\mu \mathrm{g} \mathrm{L}^{-1}$ each). The prepared reaction solution $(\mathrm{pH}=7.3)$ was subject to direct UV photolysis in the qCBA. Fig. 6 demonstrates that the experimental $k^{\prime}$ values agreed well with those predicted by Eq. (7).

It is regulated in China that the fluence should reach 20, 40

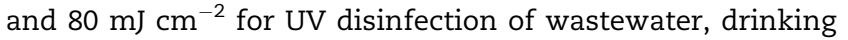
water and reclaimed water, respectively (GB/T 19837-2005, UV Disinfection Equipment for Municipal Water and Wastewater Treatment). At a typical pH of 7.5, the overall $k^{\prime}$ values of selected SAs are calculated to range from $0.6 \times 10^{-3}$ (SCP) to $20.9 \times 10^{-3}(\mathrm{SFX}) \mathrm{cm}^{2} \mathrm{~mJ}^{-1}$; hence, their removal efficiencies during UV disinfection are estimated to be in the ranges of $1-34 \%, 2-57 \%$ and $5-81 \%$ for wastewater, drinking water and reclaimed water, respectively. It is clearly seen that only part of SAs can be photodegraded in the UV disinfection process, so an advanced oxidation process (e.g., $\mathrm{UV} / \mathrm{H}_{2} \mathrm{O}_{2}$ ) is necessary if a higher removal of selected SAs is to be achieved.

\section{Conclusions}

In this study, a standard qCBA was employed to explore the UV photolysis kinetics of eight SAs in aqueous solution. The dynamic irradiance fluctuation, which had been overlooked in previous studies, was monitored by a novel MFSD in real time. Based on the experimental results, the following conclusions can be drawn:

- The optimized method could increase the accuracy in fluence quantification by up to $15 \%$, as compared to the conventional qCBA equation. 
- The photodegradation of all selected SAs followed the pseudo-first order kinetics, and the SAs with a penta-heterocycle exhibited an obviously higher photodegradation rate than those with a hexa-heterocycle.

- The solution $\mathrm{pH}$ impacted strongly the overall $\varepsilon, k^{\prime}$, and $\phi$ values of selected SAs. The specific $\varepsilon, k^{\prime}$ and $\phi$ values of the neutral and anionic species were in the ranges of $(10.8-17.0) \times 10^{3}$ and $(17.1-24.1) \times 10^{3} \mathrm{M}^{-1} \mathrm{~cm}^{-1}$, $(0.30-14.49) \times 10^{-3}$ and $(0.61-20.90) \times 10^{-3} \mathrm{~cm}^{2} \mathrm{~mJ}^{-1}$, and $(0.36-25.73) \times 10^{-2}$ and $(0.52-20.85) \times 10^{-2}$, respectively.

- At pH 7.5, the removal efficiencies of selected SAs were estimated to be $1-34 \%, 2-57 \%$ and $5-81 \%$ during UV disinfection of wastewater, drinking water and reclaimed water under the regulated fluences (i.e., 20, 40 and $80 \mathrm{~mJ} \mathrm{~cm}^{-2}$ ), respectively.

\section{Acknowledgment}

This work was financially supported by the National Natural Science Foundation of China (51290281, 51221892) and the Ministry of Science and Technology of China (2012AA062606, 2012BAJ25B04).

\section{Appendix A. Supplementary data}

Supplementary data related to this article can be found at http://dx.doi.org/10.1016/j.watres.2015.02.026.

\section{R E F E R E N C E S}

Avisar, D., Lester, Y., Mamane, H., 2010. pH induced polychromatic UV treatment for the removal of a mixture of SMX, OTC and CIP from water. J. Hazard. Mater. 175 (1), 1068-1074.

Baeza, C., Knappe, D.R.U., 2011. Transformation kinetics of biochemically active compounds in low-pressure UV photolysis and $\mathrm{UV} / \mathrm{H}_{2} \mathrm{O}_{2}$ advanced oxidation processes. Water Res. 45 (15), 4531-4543.

Birkett, J.W., Lester, J.N., 2003. Endocrine Disrupters in Wastewater and Sluge Treatment Processes. CRC Press Company, Boca Raton, America, p. 116.

Bolton, J.R., 2010. Ultraviolet Applications Handbook, third ed. ICC Lifelong Learn Inc, Edmonton, Canada, pp. 16-17.

Bolton, J.R., Linden, K.G., 2003. Standardization of methods for fluence (UV Dose) determination in bench-scale UV experiments. J. Environ. Eng.-ACSE 129 (3), 209-215.

Bolton, J.R., Stefan, M.I., 2002. Fundamental photochemical approach to the concepts of fluence (UV dose) and electrical energy efficiency in photochemical degradation reactions. Res. Chem. Intermed. 28 (7-9), 857-870.

Boreen, A.L., Arnold, W.A., McNeill, K., 2004. Photochemical fate of sulfa drugs in the aquatic environment: sulfa drugs containing five-membered heterocyclic groups. Environ. Sci. Technol. 38 (14), 3933-3940.

Burrows, H.D., Canle López, M., Santaballa, J.A., Steenken, S., 2002. Reaction pathways and mechanisms of photodegradation of pesticides. J. Photochem. Photobiol. B 67 (2), 71-108.
Capdeville, M.J., Budzinski, H., 2011. Trace-level analysis of organic contaminants in drinking waters and groundwaters. Trends Anal. Chem. 30 (4), 586-606.

Dirany, A., Sirés, I., Oturan, N., Özcan, A., Oturan, M.A., 2012. Electrochemical treatment of the antibiotic sulfachloropyridazine: kinetics, reaction pathways, and toxicity evolution. Environ. Sci. Technol. 46 (7), 4074-4082.

Elmolla, E.S., Chaudhuri, M., 2010. Comparison of different advanced oxidation processes for treatment of antibiotic aqueous solution. Desalination 256 (1), 43-47.

Fatta-Kassinos, D., Meric, S., Nikolaou, A., 2011. Pharmaceutical residues in environmental waters and wastewater: current state of knowledge and future research. Anal. Bioanal. Chem. 399 (1), 251-275.

Hess, D.A., Sisson, M.E., Suria, H., Wijsman, J., Puvanesasingham, R., Madrenas, J., Rieder, M.J., 1999. Cytotoxicity of sulfonamide reactive metabolites: apoptosis and selective toxicity of $\mathrm{CD}^{+}$cells by the hydroxylamine of sulfamethoxazole. FASEB J. 13 (13), 1688-1698.

Huang, C.L., Guo, B., Wang, X.Y., Li, J., Zhu, W.T., Chen, B., Ouyang, S., Yao, S.Z., 2012. A generic approach for expanding homolog-targeted residue screening of sulfonamides using a fast matrix separation and class-specific fragmentationdependent acquisition with a hybrid quadrupole-linear ion trap mass spectrometer. Anal. Chim. Acta 737, 83-98.

Lanuza, M.P., 2010. Pharmaceuticals and Personal Care Products in Environmental Waters. Universitat Rovira I Virgili, Tarragona, Spain, pp. 58-59.

Le, T.X., Munekage, Y., Kato, S.-I., 2005. Antibiotic resistance in bacteria from shrimp farming in mangrove areas. Sci. Total Environ. 349 (1-3), 95-105.

Lester, Y., Mamane, H., Avisar, D., 2012. Enhanced removal of micropollutants from groundwater, using $\mathrm{pH}$ modification coupled with photolysis. Water Air Soil Pollut. 223 (4), 1639-1647.

Li, J., Blatchley III, E.R., 2008. UV photodegradation of inorganic chloramines. Environ. Sci. Technol. 43 (1), 60-65.

Li, M.K., Qiang, Z.M., Bolton, J.R., Ben, W.W., 2012. Impact of reflection on the fluence rate distribution in a UV reactor with various inner walls as measured using a micro-fluorescent silica detector. Water Res. 46 (11), 3595-3602.

Li, M.K., Qiang, Z.M., Li, T.G., Bolton, J.R., Liu, C.L., 2011. In situ measurement of UV fluence rate distribution by use of a micro fluorescent silica detector. Environ. Sci. Technol. 45 (7), 3034-3039.

Parkinson, A., Barry, M.J., Roddick, F.A., Hobday, M.D., 2001. Preliminary toxicity assessment of water after treatment with UV-irradiation and UVC/ $\mathrm{H}_{2} \mathrm{O}_{2}$. Water Res. 35 (15), 3656-3664.

Pereira, V.J., Weinberg, H.S., Linden, K.G., Singer, P.C., 2007. UV degradation kinetics and modeling of pharmaceutical compounds in laboratory grade and surface water via direct and indirect photolysis at $254 \mathrm{~nm}$. Environ. Sci. Technol. 41 (5), $1682-1688$.

Qiang, Z.M., Adams, C., 2004. Potentiometric determination of acid dissociation constants $\left(\mathrm{pK}_{\mathrm{a}}\right)$ for human and veterinary antibiotics. Water Res. 38 (12), 2874-2890.

Qiang, Z.M., Li, M.K., Bolton, J.R., 2013. Development of a triparameter online monitoring system for UV disinfection reactors. Chem. Eng. J. 222, 101-107.

Rivas, J., Gimeno, O., Borralho, T., Sagasti, J., 2011. UV-C and UV$\mathrm{C} /$ peroxide elimination of selected pharmaceuticals in secondary effluents. Desalination 279 (1), 115-120.

Yuan, F., Hu, C., Hu, X.X., Wei, D.B., Chen, Y., Qu, J.H., 2011. Photodegradation and toxicity changes of antibiotics in UV and $\mathrm{UV} / \mathrm{H}_{2} \mathrm{O}_{2}$ process. J. Hazard. Mater. 185 (2), 1256-1263. 